Vol. 4, No. 1, 2018

\author{
Petro Hashchuk ${ }^{1}$, Serhij Nikipchuk ${ }^{2}$ \\ ${ }^{1}$ Department of Operation of Vehicle and Fire-rescue Techniques, Lviv State University of Life Safety, \\ 35, Kleparivska Str., Lviv, Ukraine, E-mail: petroh@meta.ua \\ ${ }^{2}$ Department of Operation and Repair of Automotive Vehicles, Lviv Polytechnic National University, \\ 32, S. Bandera Str., Lviv, Ukraine, E-mail: serhij.v.nikipchuk@lpnu.ua
}

\title{
HEAT GENERATION AND HEAT CONSUMPTION IN ENGINE OF RAPID INTERNAL COMBUSTION
}

Received: May 22, 2018 / Revised: June 22, 2018 / Accepted: June 26, 2018

(C) Hashchuk P., Nikipchuk S., 2018

Abstract. The research of heat generation and heat consumption in a conventional or ideal engine provides useful information about the regularities, character of the process and effectiveness of fuel combustion in any real engine that cannot be subject to experiments. This information is advantageous both in case of heat transformation effectiveness analysis and the development of means to improve already employed engine. The procedure (algorithm) of thermal processes modeling that take place in the internal combustion engines should be developed in a way that enables, according to measured pressure of working gases, to adequately reconstruct the course of heat generation, and vice versa, relying on a set course of heat generation, to veritably identify the change of gases pressure in the cylinder. Research aim - based on the principle of analogy and harmonious combination of induction and deduction to evaluate the possibility to represent in a formal way and theoretically generalize experimentally identified information about the regularities of heat generation and heat consumption processes development in Otto-cycle engines (engines of rapid internal combustion). As a rule in case of analytical identification of heat generation - heat consumption processes the index $a$ of combustion capacity is defined in advance. The acquired information, however, demonstrates that there are more reasons to consider the value of the parameter $m$ to be set in advance, rather than of the parameter $a$. The relation between values of heat emission maximal intensiveness $\&$ and the time of its achievement $\tau *$ in an empirical sense is seemingly parabolic. Theoretically, as it has been found out, it can be evidently treated as "fuzzy" hyperbolic. The fact that the engine's idle run does not conform to the "hyperbolic" tendency manifests its considerable imperfection and does not contend against the theoretically substantiated regularity. Given, for example, that $\varepsilon^{*} \tau^{*} \approx 1$, it is possible to acknowledge that $m \approx 1.93$. While given $m \approx 2$, we will have to acknowledge that $\approx * \approx 1.03$. Thus, if we assign in advance that $a=-6.908$ we considerably limit the flexibility and preciseness of the identification algorism.

Keywords: internal combustion engine, operating cycle, heat generation, heat consumption, combustion process, Wiebe function, heat generation programs.

\section{Introduction}

The study of internal combustion engines operating cycles makes it possible to intentionallypurposely obtain practically important data about the influence of constructive, regulatory, regime factors on the efficiency and perfection of a thermal machine. The information about the course of heat generation is applicable both in the design of a completely new engine and in case of analysis of heat transformation effectiveness and the development of means to improve already existing models.

The study of heat generation/heat consumption phenomena in the internal combustion engines subordinates to certain conventional conceptions. We can consider the study [1] as an example of deep theoretical generalization: it, based on the principles of exergy analysis, evaluates what amount of energy released in the process of fuel combustion under the elementary movement of the piston even theoretically 
cannot be transformed into the expansion work $p d V$ ( $p$ - pressure in the cylinder, $V$ - volume of the working medium); within the framework of this approach the complex real process is mentally subdivided into the elementary processes equivalent to it and the analysis is carried out with application of special diagrams for the combustion materials. However, in most cases the researchers rely on the formalized description of kinetic chemical transformations in the working space of the engine [2,3], making conclusions based on semi-empirical descriptions of "thermal" consequences. Wiebe function is a sample of the heat generation processes description of this kind [4-6]. In [4] the exactness of heat emission process reconstruction is directly analyzed as two-parameter and optimized one according four parameters of Wiebe functions, and for the description of operation cycles with detonation combustion a balanced linear combination of two Wiebe functions is defined. In [5] it is emphasized that Wiebe function, similar to many other suggested functions of heat generation, is based on the so called law of normal distribution of the variate and enables to acceptably qualitatively prognosticate the intensiveness of heat emission in the internal combustion engines which are characterized by different systems of fuel combustion - diesel with direct (DI - direct injection) and diesel with indirect (IDI - indirect injection) fuel injection, classic engines with spar ignition (SI - spark ignition), engines with gasoline direct injection (GDI - gasoline direct injection), the so called engines with homogeneous charge compression ignition HCCI (homogeneous charge compression ignition) and engines PCCI (premixed charge compression ignition). The research [6] studies the sensitivity of Wiebe function parameters (in particular the efficiency coefficient $a$ and function form $m$ ) to the peculiarities of the real operation process.

The procedure (algorithm) of thermal processes modeling that take place in the internal combustion engines should be developed in a way that enables, according to measured pressure of working gases, to adequately reconstruct the course of heat generation, and vice versa, relying on a set course of heat generation, to veritably identify the change of gases pressure in the cylinder. In particular, it goes without saying, that in case of a new engine design the change of gases pressure in its working space is unknown. Thus, the research should be based on the course of heat generation in a similar or exemplary engine or different hypothetical or intentional processes of heat generation should be defined and studied in the respect of their impact on the character of combustion and efficiency of the engine.

\section{Research Aim}

Based on the principle of analogy and harmonious combination of induction and deduction to evaluate the possibility to represent in a formal way and theoretically generalize experimentally identified information about the regularities of heat generation and heat consumption processes development in Ottocycle engines (engines of rapid internal combustion).

\section{Real Heat Generation}

Fig. 1, as an example, represents the graphs depicting the course of heat generation, identified with the help of two-region model of otto-cycle engine working space, combined with the parallel experiment in case of equal frequency of engine shaft rotation $n_{e}=2400 \mathrm{~min}^{-1}$ and different engine load measured by mean effective pressure $p_{e}$. Whereas the fig. 2 represents the course of heat generation, on the contrary, under different frequencies of engine shaft rotation and similar engine load $p_{e}=0.30 \mathrm{MPa}$. Obviously, it is far from easy to suggest any analytical formalization of heat generation characteristics.

Notably, when the load increases the maximum intensity (velocity, capacity) of heat generation escalates and shifts towards the top dead center position (TDC) of the piston while the duration of the combustion process decreases. Thus, when the load is $p_{e}=0.10 \mathrm{MPa}$ (see Fig. 1) the time of combustion is 104.32 degrees of engine shaft rotation and when $p_{e}=0.45 \mathrm{MPa}$ it drops to 77.38 degrees. Herewith, the beginning of combustion in the first case corresponds to the angle -10.75 degrees, in the second - to the angle -13.48 degrees. When the frequency of the engine rotation increases (see Fig. 2) the production of heat in the proximity of the TDC position becomes less intensive and protracted according to the angle of the engine shaft turnover. 


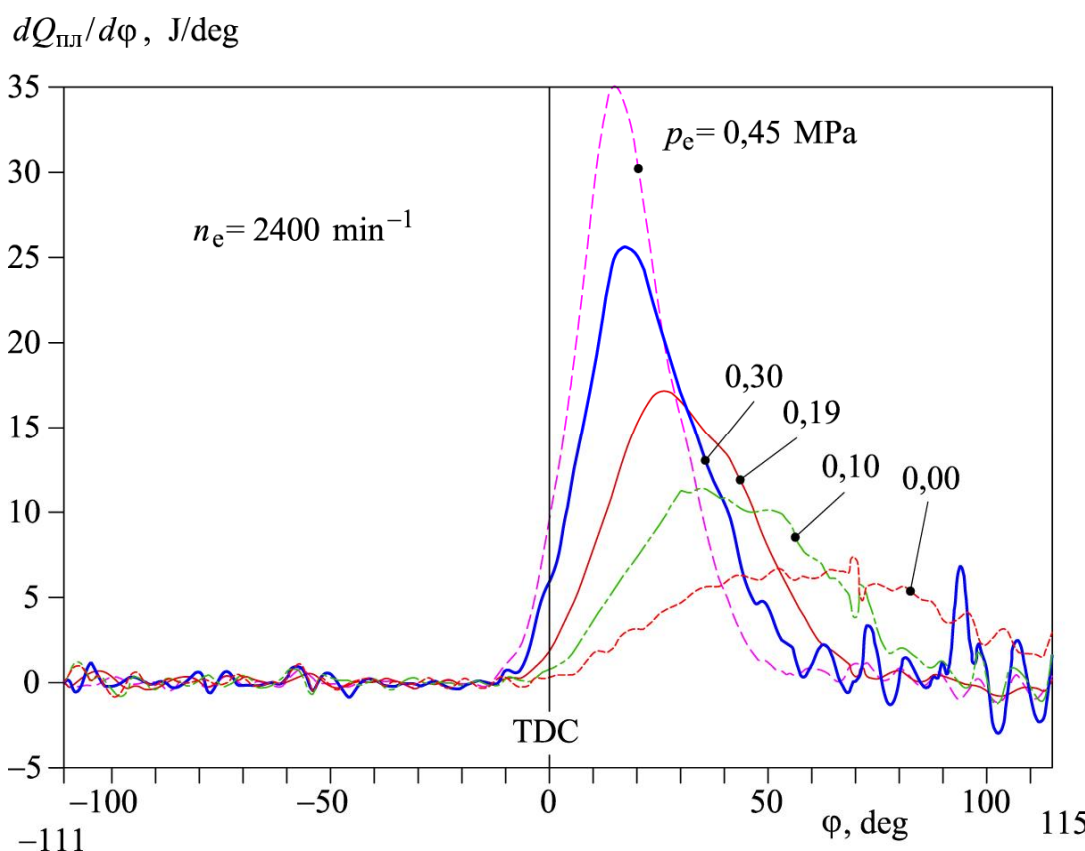

Fig. 1. Graphs of change of heat generation intensity in case of equal speed of engine shaft rotation and different engine loads

$d Q_{\text {плл }} / d \varphi, \mathrm{J} / \mathrm{deg}$

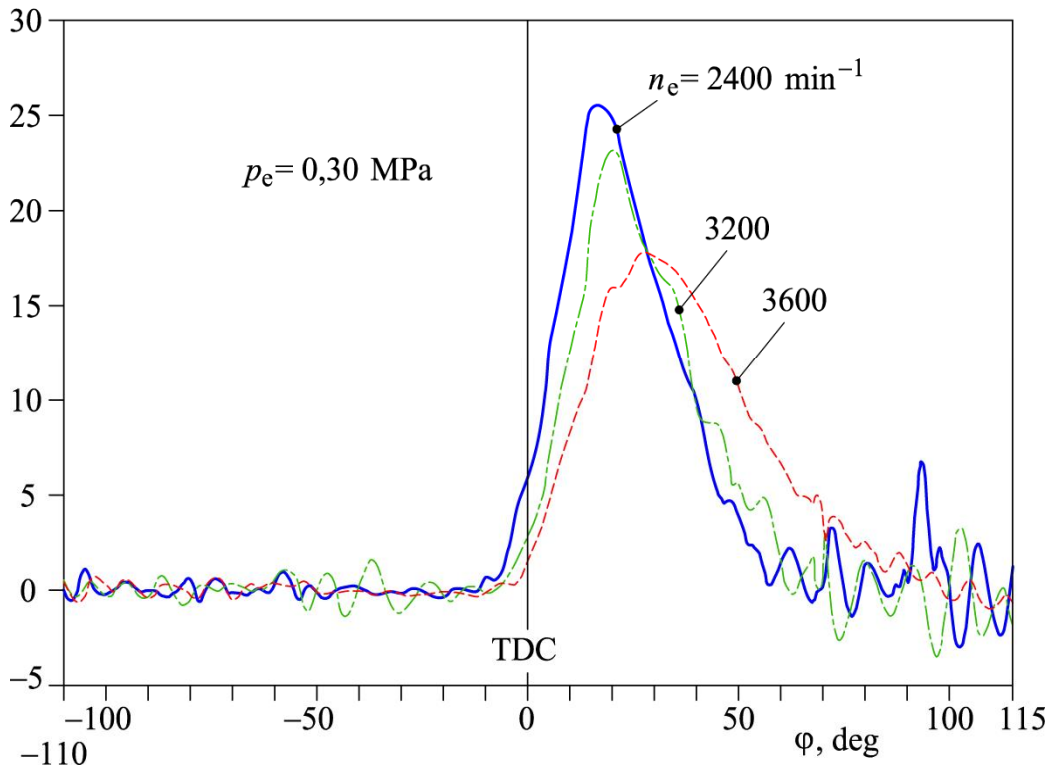

Fig. 2. Graphs of change of heat generation intensity in case of equal engine load and different frequency of engine shaft rotation

\section{Ideal Heat Generation}

It is a common knowledge that the famous engineer Rúdolf Diésel designing his "rational engine" put forward three requirements to the working cycle: 1) that the maximal temperature of the cycle be achieved before the beginning of the combustion process; 2) that the isothermality of combustion be secured by gradual injection of finely pulverized fuel: 3 ) the operability of the engine be secured without its cooling. The idea, in fact, implied the implementation of Carnot cycle and achievement in a completely satisfactory temperature range $280-1000 \mathrm{~K}$ of the highest possible thermal coefficient of engine operation efficiency $\eta_{t}=(1000-280) / 1000=0,72$. However, after a while he had to abandon the ephemeral theory and become aware of a rough reality: the indicated pressure suffices only to provide free running of the 
engine. Thus it was decided to accelerate the process of fuel injection into the working space with isobaric rather than isothermal burning. The mean indicated pressure, in its turn, increased considerably, with a simultaneous increase of fuel burning temperature to $1800 \mathrm{~K}$ which led to the necessity to cool the walls and head of the cylinder. Diésel's ideas failed.

Generally, comparing the real and ideal engines usually three types of heat generation (provision of heat) are distinguished: isobaric (constant pressure $-p=$ const); isochoric (constant volume of the working space $v=$ const ); and combined [7-9]. Fig. 3 schematically (in a simplified way) depicts the cycle with an isobaric supply of a certain amount of heat $Q_{\mathrm{e}}\left(p\right.$ - current pressure; $v$-current volume of the working space; $V_{c}$ and $V_{h}$ - clearance volume and cylinder capability; $\varphi$ - the angle of the shaft turnover; TDC and BDC - top and bottom dead center positions; $q_{\mathrm{e}}$ - current volume of supplied heat). Certainly, the process of heat generation (provision of heat) even in case of defined condition $p=$ const is not single-valued: for example, the speed of heat generation $d q_{\mathrm{e}} / d \varphi$ can be proportional to the working space $v-V_{c}$ or to the angle of engine shift turnover $\varphi$ (Fig. 3), or can be an arbitrary function of $v-V_{c}$ and $\varphi$ values.

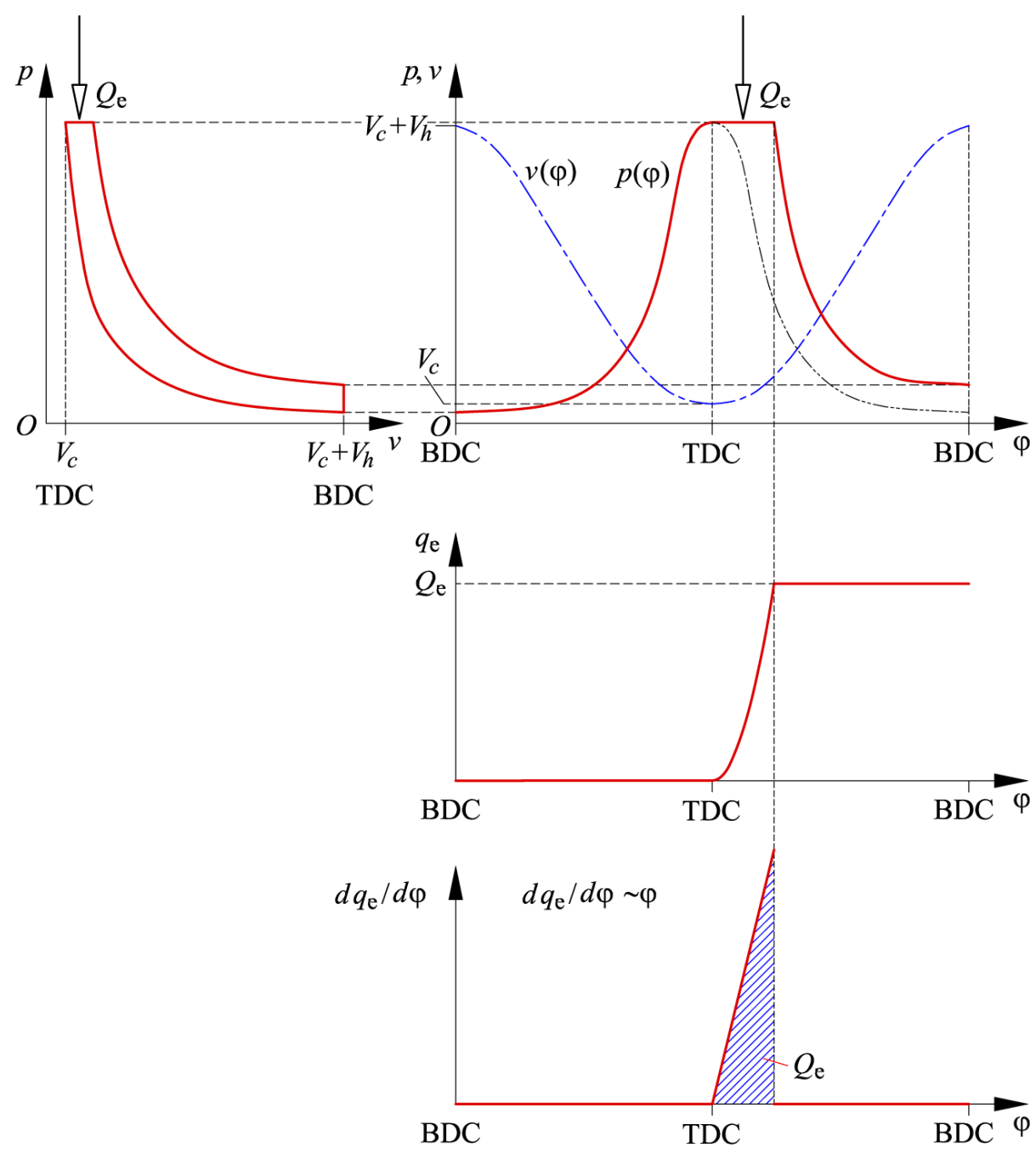

Fig. 3. Draft of the ideal cycle with isobaric heat generation-application

Isochoric process (Fig. 4) can be formally represented by the following formula

$$
q_{\mathrm{e}}=Q_{\mathrm{e}} \delta(\varphi)=Q_{\mathrm{e}} \delta\left(v-V_{c}\right),
$$

where $\delta(\cdot)$ - is Dirac delta function. The capacity of isochoric heat generation takes the form of a singular rectangle of the defined area $Q_{\mathrm{e}}$ which altitude indefinitely increases and the latitude tends to zero. In 
isochoric-isobaric process the share of heat $Q_{\mathrm{e}}^{\prime}$ is provided to the working medium of the working space, whereas the share $Q_{\mathrm{e}}^{\prime \prime}$ - under the constant pressure in it.

Fig. 5 schematically depicts the graphs of some special types of heat generation processes. The generation of heat in a real engine seems to have nothing in common with either isochoric or isobaric heat generation. For example, the picture below represents qualitative comparison of heat generation processes in diesel engines with three types of combustion chambers.
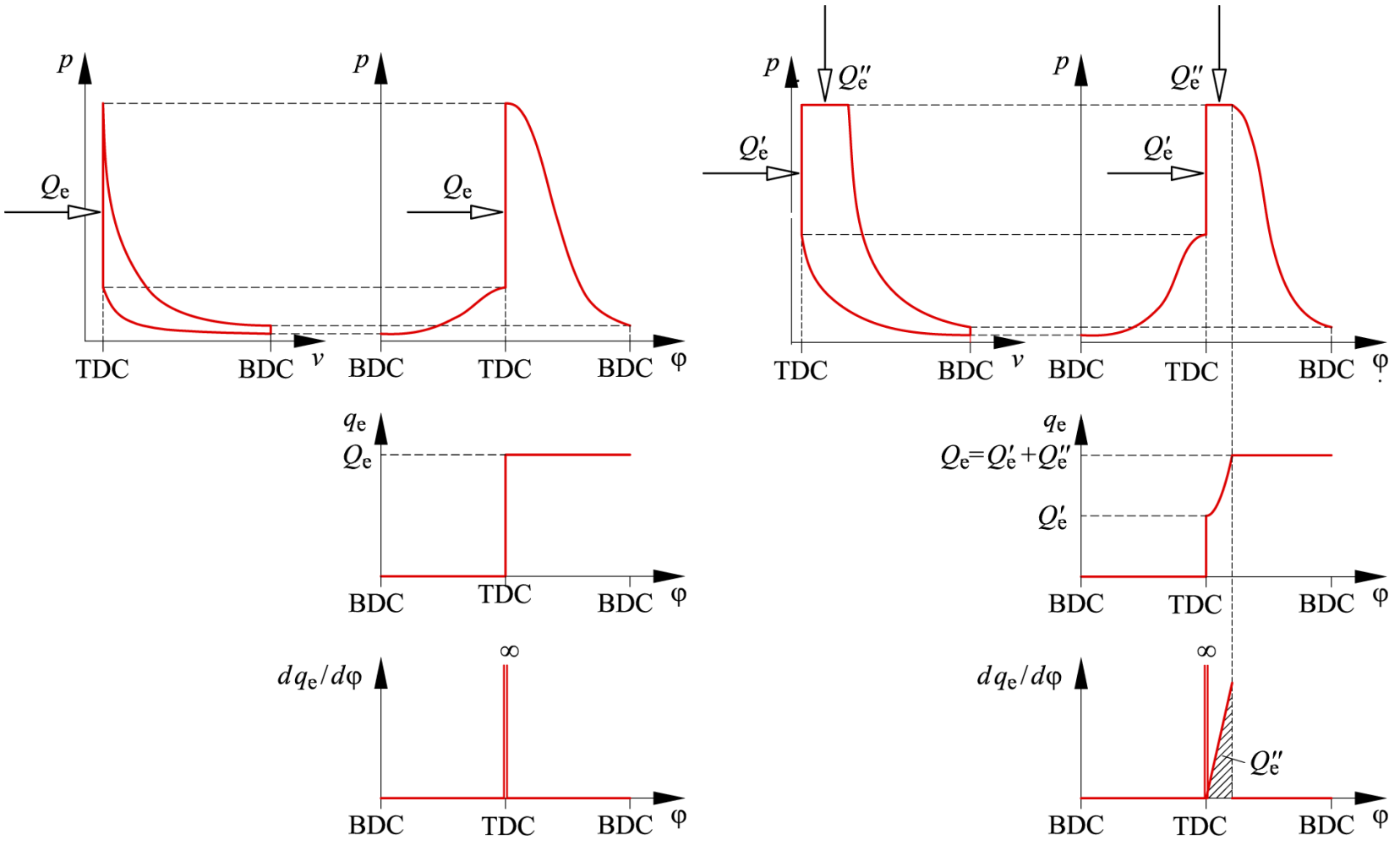

Fig. 4. Drafts of the ideal cycles with isochoric (to the left) and isochoric-isobaric processes of heat generation-heat application

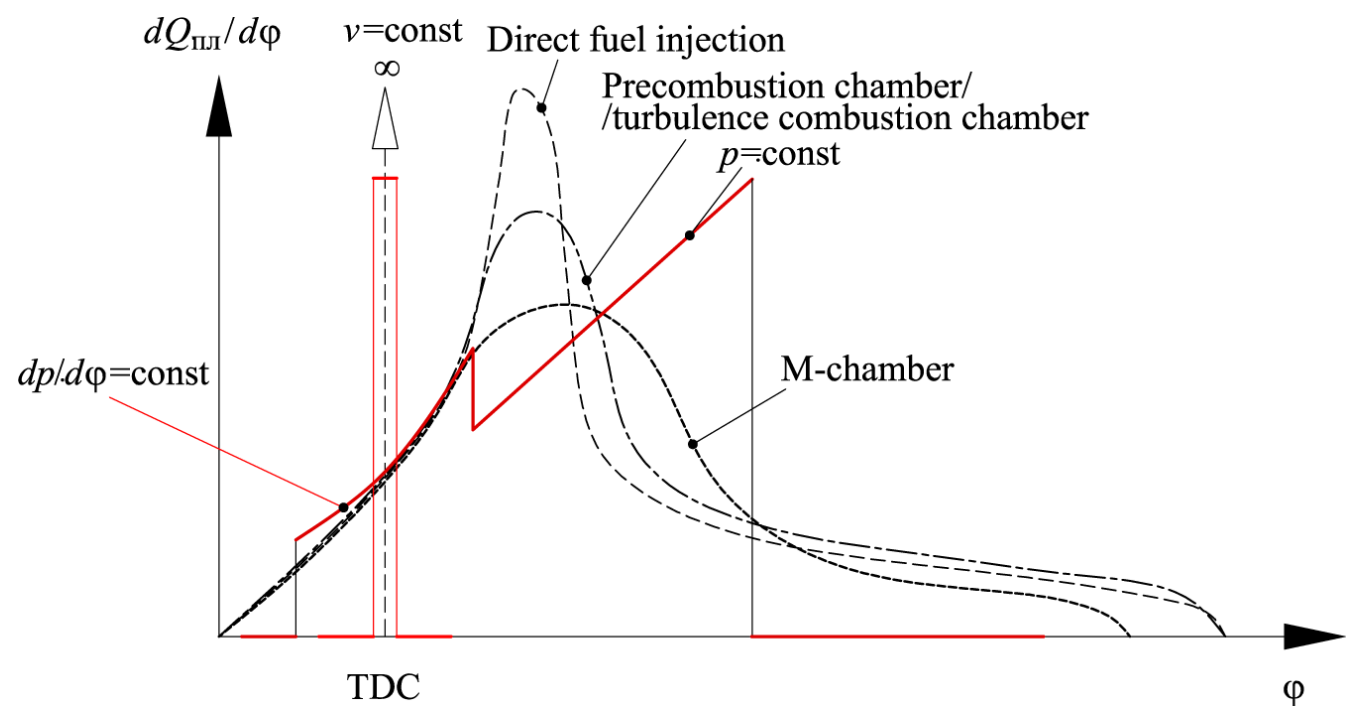

Fig. 5. Qualitative comparison of principally different heat generation processes

The formal comparison of data represented in Figs. 1, 2 with the ones represented in Fig. 3 suggests that the real heat generation processes (see Figs. 1 and 2) in its initial (virtually linear) phase are isobaric (see Fig. 3). However, the indicated diagrams refute these assumptions. The assumption that the real 
generation starts before the top dead center position in case of isobaric process would imply a considerable imperfection or even directness of the thermal dynamic cycle. There are no signs of isochoric process to be observed, either - let us compare Figs. 1 and 2 with Fig. 4.

Let us recall that [10]: otto-engine was referred to as rapid combustion, whereas diesel-engine as engine of gradual combustion.

\section{Fuel Burnout Diagrams}

Concerning diesel engines usually three phases of burnout processes are distinguished (Fig. 6). During the first phase (section $\mathrm{Oa}$ in Fig. 6) the emission of heat is accompanied by intensive heating and evaporation of fuel as well as by superheating of its vapors - the loss of heat prevails over its emission. In the second one (the section $a b$ ) it is usually the mixture that comes into being in the period of sparking delay that burns out. This phase is referred to as kinetic [11], because it is considered to run in accordance with kinetic chemical reactions. The third phase (section $b c$ ) is referred to as diffusive [11], since the rate of reactions of fuel burn-out is determined by the rate of mixture formation in the result of turbulent mixing ( the rate of chemical reactions is high as a result of high temperatures of working charge). In some cases the fourth phase of heat emission has to be defined (the phase of fuel burn down) with low rates. It can be defined on the curve of heat emission (capacity) created in logarithmic coordinates: the deceleration of mixture and heat production is traced according to the rotation angle for the straight tangent line to the curve.

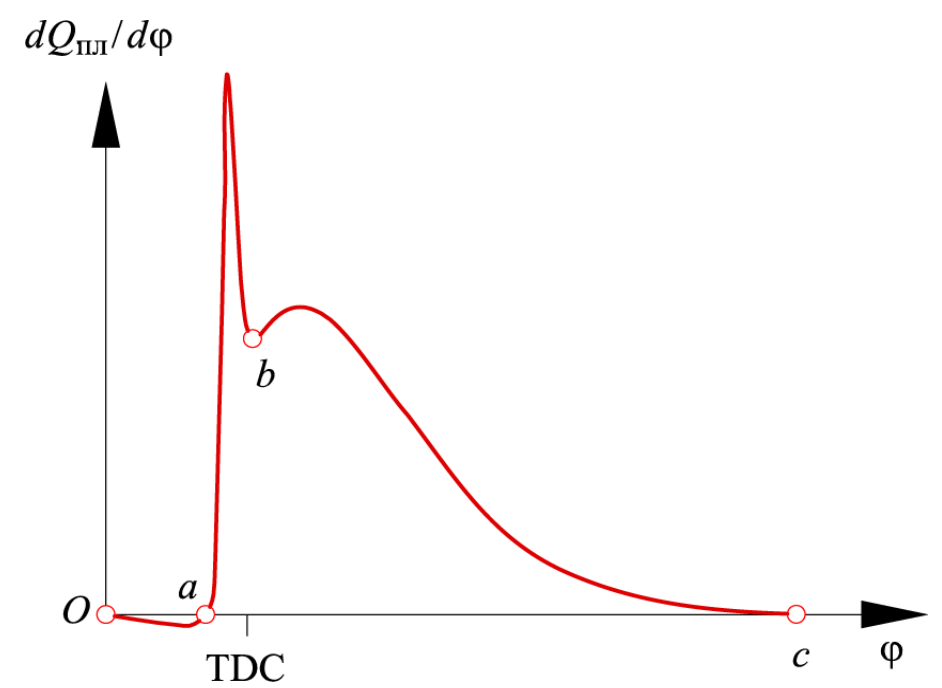

Fig. 6. Typical course of heat generation in a conventional diesel engine

The shares of heat burnt -out during the second and the third phases of heat generation are defined [8] by the following formulas

$$
\begin{gathered}
z=Z_{1}\left(1-e^{a\left(\varphi / \varphi_{z 0}\right)^{m_{0}+1}}\right)+Z_{2}\left(1-e^{a\left(\varphi / \varphi_{z}\right)^{m+1}}\right), \varphi \leq \varphi_{z 0}, \\
z=Z_{1}+Z_{2}\left(1-e^{a\left(\varphi / \varphi_{z}\right)^{m+1}}\right), \varphi>\varphi_{z 0},
\end{gathered}
$$

where $Z_{1}$ and $Z_{2}\left(Z_{1}+Z_{2}=1\right)$ - shares of fuel that are likely to burn out during the second and the third phases of heat generation process; $a=-6.908$ - parameter that characterizes level of fuel general burn-out within the engine working space; $m_{0}$ and $m$ - values of burn-out in the second and third phases; $\varphi-$ current angle of shoulder shaft turnover which timing starts at the moment of sparking; $\varphi_{z 0}$ and $\varphi_{z}-$ duration of the second and third phases in angled measurement. In particular, the process $a b c$ represented in Fig. 4 can be acceptably and adequately described by expressions (1) .

Concerning special processes of heat generation (see, as an example, [12]) more constituents can be applied in description (1), as if we distinguished more phases of fuel bourn-out. However, spark-ignition 
engines (Otto-engines) are characterized by single-phase heat generation. Thus the heat generation in ottoengine can be described by exponential correlation [13-15]

$$
z=1-\exp \left(a \tau^{m+1}\right),
$$

where $z=Q_{\mathrm{T}} / Q_{\mathrm{TЦ}}-$ is relative (specific) heat generation; $Q_{\mathrm{T}}-$ current heat generation; $Q_{\mathrm{TЦ}}-$ general potential heat generation per operating cycle;

$$
\tau=\frac{t-t_{\Pi}}{t_{\mathrm{K}}-t_{\Pi}}=\frac{\varphi-\varphi_{\Pi}}{\varphi_{\mathrm{K}}-\varphi_{\Pi}},
$$

is relative (abstract, dimensionless) time; $t$-current time; $t_{\Pi}$ and $t_{\mathrm{K}}$ - the start and completion moments of fuel burning within the working space; $\varphi_{\Pi}$ and $\varphi_{\kappa}$ - angles of crankshaft turn-over that correspond to the start and completion moments of fuel burning; $m>0$ - characteristic index of combustion quality; $a-$ constant that characterizes the quality of combustion.

According to (2), (3) the (2), (3) change of heat generation intensiveness in an abstract time is described by the formula

$$
\frac{d z}{d \tau}=\tau_{0} \frac{d z}{d t}=-a(m+1) \tau^{m} \exp \left(a \tau^{m+1}\right)=a(m+1) \tau^{m}(z-1),
$$

where $\tau_{0}=t_{\mathrm{K}}-t_{\Pi}-$ duration of heat generation process within the engine's working space. It is obvious that

$$
\frac{d z}{d \tau}=\frac{1}{Q_{\mathrm{T}}} \frac{d Q_{\mathrm{T}}}{d \tau}=\frac{\varphi_{\mathrm{K}}-\varphi_{\Pi}}{Q_{\mathrm{T}}} \frac{d Q_{\mathrm{T}}}{d \varphi} .
$$

If, for example, $z\left(t_{\mathrm{K}}\right)=z_{\mathrm{K}}=0.999$, then $a=\ln \left(1-z_{\mathrm{K}}\right)=\ln (1-0.999)=-6.908$, if $z_{\mathrm{K}}=0.99$, then $a=-4.605$, and if $z_{\mathrm{K}}=0.9$, then $a \approx-2,303$. Fig. 7, as an example, depicts the heat generation programs (4) and (5) in case of lower $\left(z_{\mathrm{K}}=0.9, a=-2.303\right)$, and Fig. 8 - in case of higher rate of fuel burn-out $\left(z_{\mathrm{K}}=0.99, a=-4,605\right)$. Points corresponding to extreme heat emission under all possible values of parameter $m$ belong to curves $E$. The higher is the value of parameter $m$, the later occurs the phase of the most active emission of heat. The higher is $m$ and the lower $z_{\mathrm{K}}$ the more active is heat emission in terminal moment $\tau=1$ of heat generation process.

Fig. 9 separately differentiates the heat generation programs that correspond to information represented in Fig. 7, 8 (by the dashed-line curve) in case of the lowest $m=0$ and in case of the highest $m=20$. It is evident that in case of $a \rightarrow-\infty, m=0$ the heat generation becomes quasi-isochoric - the largest amount of heat is produced in the moment $\tau \rightarrow 0$. It also becomes quasi-isochoric in case of $m \rightarrow \infty-$ the considerable amount of heat is produced in the moment $\tau \rightarrow 1$. In the first case the ignition is to occur in the highest dead point and the burn-out at the combustion stroke; in the second case the ignition is to occur at the pressure stroke and to complete in the upper dead point. In fact, it is unconditionally considered [12-14] that usually over the operating period the constant share of fuel $z=0,999$ burns out, hence, $a=\ln \left(1-z_{\mathrm{K}}\right)=\ln (1-0.999)=-6.908$.

Isochoric thermodynamic cycle serves as an ideal example for Otto-engine operating cycle. Thus the correlation $\eta_{\text {vзг }}$ of operation in a real process to the operation in an isochoric one can be regarded as index of similarity between real heat generation and ideal isochoric heat production processes. Herewith, the amount of heat provided to the working medium in the compared processes must be equal. The similar context implies the rate $\eta_{v_{ц}}$ of isochoric character of heat loss into the cylinder walls in the real operating cycle. However, it does not bring much benefit. 


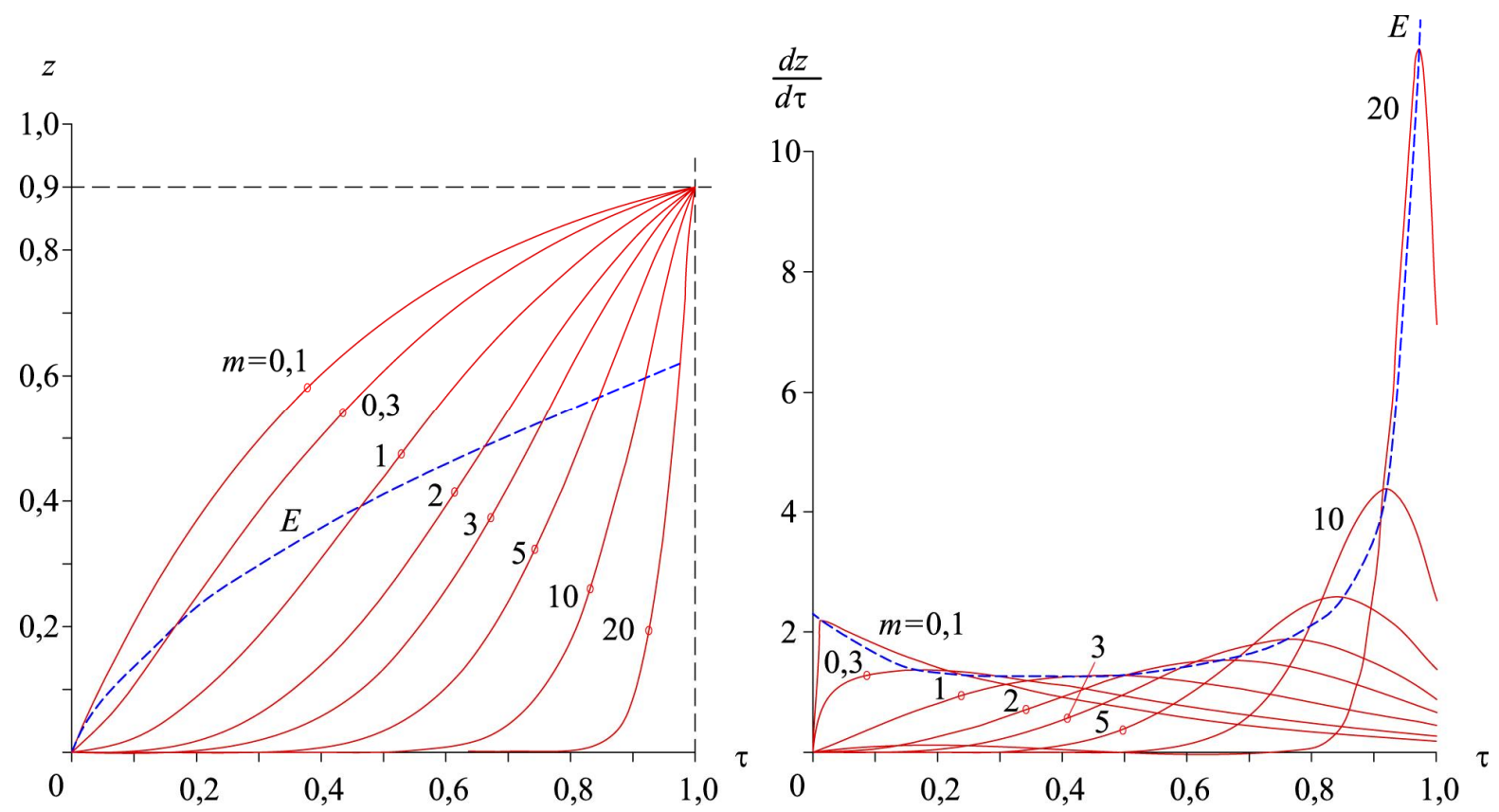

Fig. 7. Heat generation programs in case of lower rate of fuel burn-out
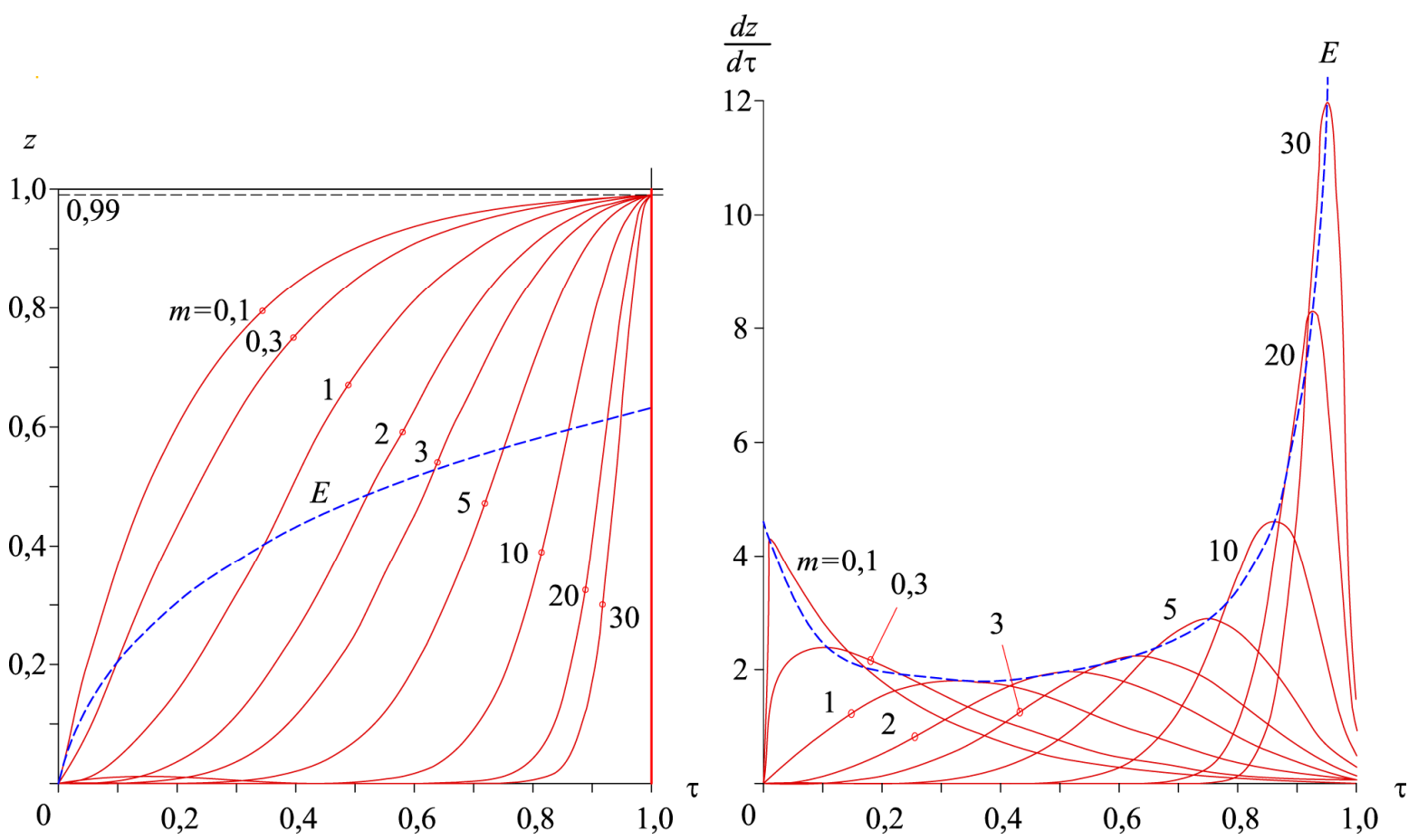

Fig. 8. Heat generation programs in case of higher rate of fuel burn-out

Numerous experiments have determined and asserted, referring to the authoritative sources, certain features of a typical course of processes in the engine's cylinder which are represented in Fig. 10 graphically and concisely ( $\eta$ - the efficiency coefficient). In particular, the heat generation process is to start before the highest dead point and should not be excessively long. The barycenter of the area under the heat generation curve is located just behind the dead point. Thus, neither isochoric, nor isobaric types can be regarded as guidelines of heat generation mechanism improvement.

It is also worth mentioning that classic diesel engines are distinguished by smoother heat generation characteristics than those represented in Fig. 6 (see, as an example, [16]). And very often these characteristics and the content of otto-engines' characteristics are analogous [17, 18]. 


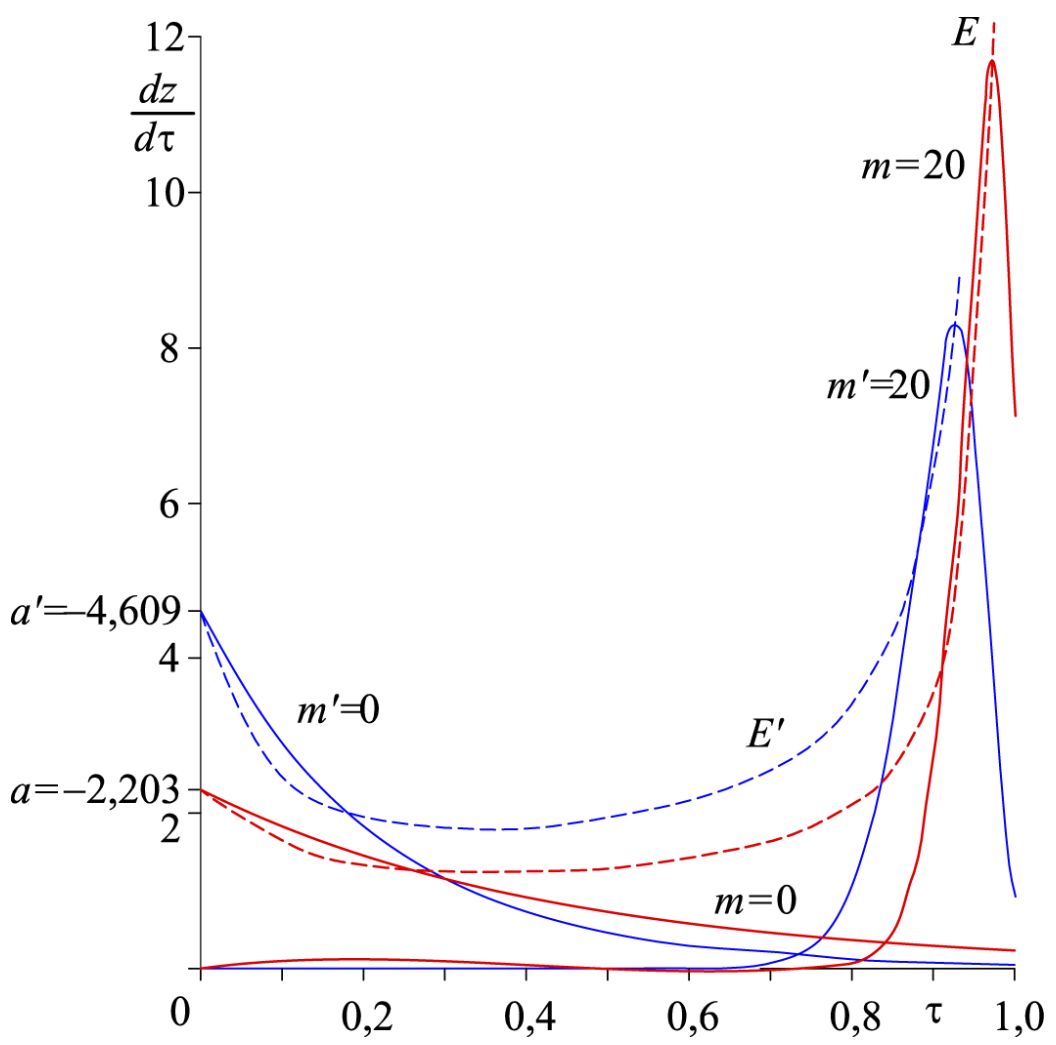

Fig. 9. Special programs of heat generation
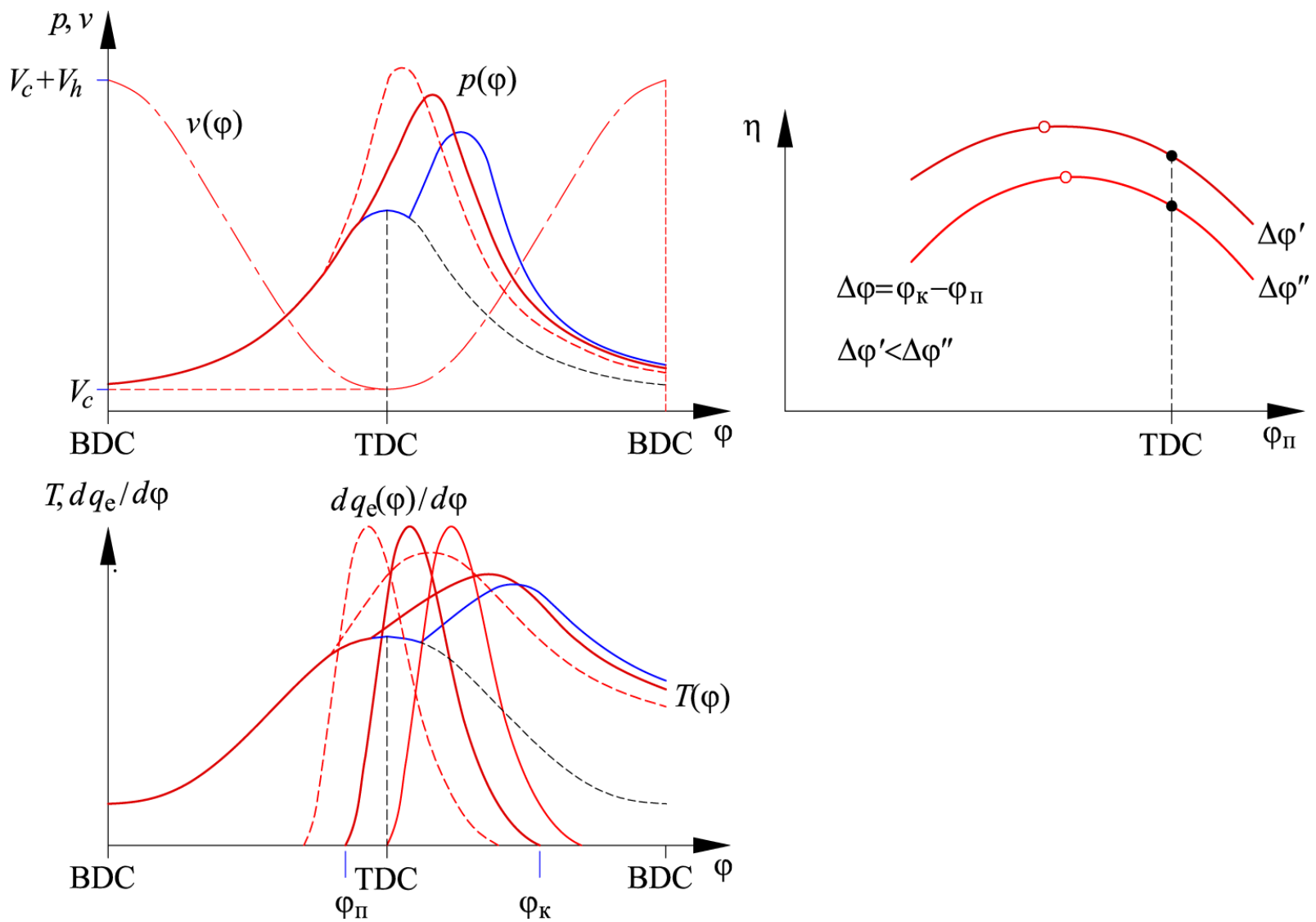

Fig. 10. Typical correlation between the processes of characteristic quantities changes 


\section{Heat Rejection and Heat Consumption}

A certain amount of heat constrainedly penetrates outside the cylinder with no tangible benefits [19]. Fig. 11 represents the graphs of heat irradiation into the cylinder walls under certain operation modes of the engine. The suggested information implies that under a constant frequency of the shaft rotation and the acceleration of working load the amount of heat irradiated into the surface of the cylinder increases, whereas under the constant working load and the increase of the shaft rotation frequency it decreases. Consequently, the irradiation of heat into the cylinder walls is the lowest under the maximal shaft rotation frequency and its minimal working load.

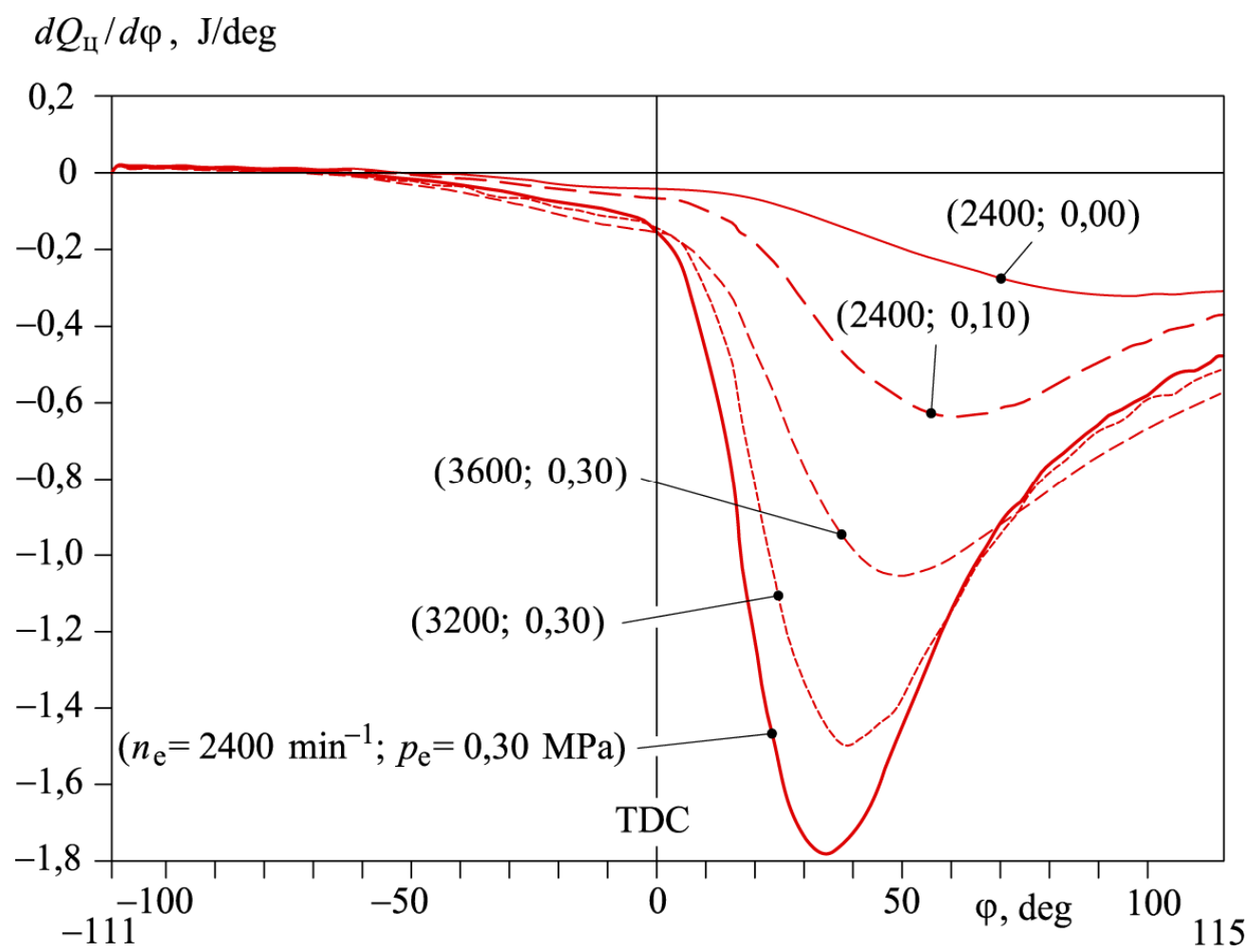

Fig. 11. Transmission of heat into the cylinder walls

The heat rejection into the cylinder walls consists of three components:

$$
d Q_{\mathrm{L}}=d Q_{\mathrm{L \Pi}}+d Q_{\mathrm{LK}}+d Q_{\mathrm{L \Gamma}},
$$

where $d Q_{\mathrm{L \Pi}}$ - is (an elementary) heat transmission into the piston; $d Q_{\mathrm{LK}}-$ heat transmission into the head (lid) of the cylinder; $d Q_{\mathrm{L \Gamma}}$ - heat transmission into the cylinder liner. The graphs of the listed components $d Q_{\mathrm{L \Pi}}, d Q_{\mathrm{LK}}$ and $d Q_{\mathrm{L \Gamma}}$ changes are represented in Fig. 12 (the engine operation mode under consideration is the following $\left(n_{\mathrm{e}}=2400 \mathrm{~min}^{-1}, p_{\mathrm{e}}=0.30 \mathrm{MPa}\right)$ ). The most prominent is the component $d Q_{\mathrm{LK}}-$ the greatest amount of heat is lost through the cylinder head (lid). The transmission of heat into the cylinder liner $d Q_{\mathrm{L} \Gamma}$ is mostly preconditioned by the fact that surface area of heat irradiation varies in the process of heat generation. This condition, to a certain extend, has an impact on other constituents of heat loss. Generally, it is uselessly to expect that both the mentioned components and their totality can be approximated by the expressions of similar structure.

The difference between heat generation and heat leakage (transmission of heat into the cylinder walls) can be considered as heat consumption. As an example, in Fig. 13 for one of previously defined engine's operation mode based on the Figs. 1 and 11 there is created the graph of heat consumption HC (HG - the graph of heat generation, HL - the graph of heat leakage) the fluctuations of the graphs have been leveled out. 


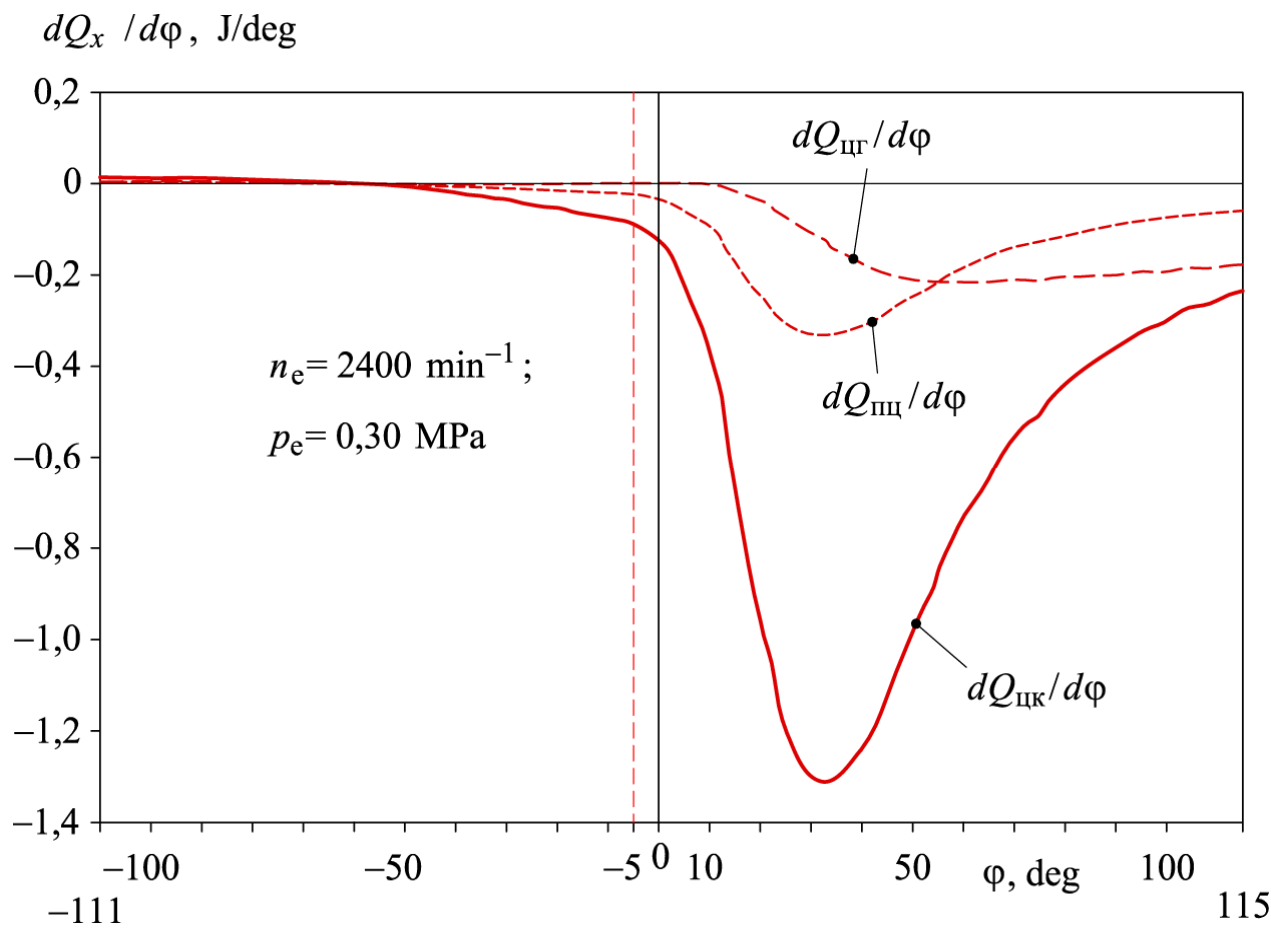

Fig. 12. Separate components of heat transmission into the cylinder walls $d Q_{\text {пл }} / d \varphi, \mathrm{J} / \mathrm{deg}$

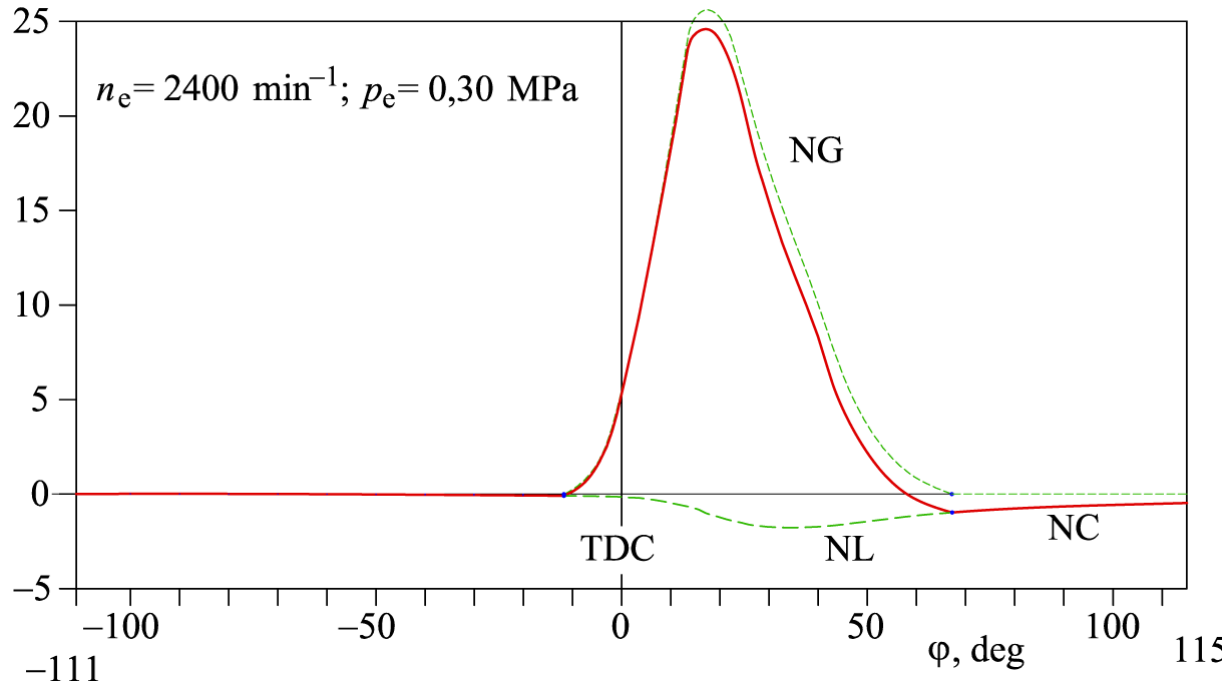

Fig. 13. Graph of heat consumption

\section{Specific Generalizations}

In a formal way, approximated dependencies (2) and (4), that describe the process of heat generation depend on two parameters $-a$ (or $z_{\mathrm{K}}$ ) and $m$. But physically (see also (3)) there are four influencing parameters: $a$ (or $z_{\mathrm{K}}$ ), $m, \varphi_{\Pi}, \Delta \varphi=\varphi_{\mathrm{K}}-\varphi_{\Pi}$. Thus, reasonably changing the listed parameters it is possible to observe their influence on the character of heat generation process as well as on the values determinant for the assessment of engine operation including maximal pressure and temperature of gases in the process of combustion, mean indicated pressure, coefficient of efficiency, specific loss of fuel, etc.

However, the parameters $a$ (or $z_{\mathrm{K}}$ ) are often set in advance, deliberately decreasing in that way the number of freeness stages per unit. The fixed parameter $z_{\mathrm{K}}$ (or $a$ ) considerably limits the flexibility of the 
approximation means. For example, in case of $z_{\mathrm{K}}=0.999$ (or $a=-6.908$ ) the conventional duration $\tau_{1 / 2}$ of $1 / 2$ portion of fuel burn-out satisfies the stringent condition

$$
\tau_{1 / 2}^{m+1}=\frac{\ln \frac{1}{2}}{a}=\frac{\ln \frac{1}{2}}{\ln \left(1-z_{\mathrm{K}}\right)} \approx 1 / 10 .
$$

In case of $z_{\mathrm{K}}=0.99(a=-4.605)-\tau_{1 / 2}^{m+1} \approx 0.15$, and in case of $z_{\mathrm{K}}=0.9 \quad(a=-2.303)-$ $\tau_{1 / 2}^{m+1} \approx 0.30$. To prove this regularity experimentally is not possible.

In the table there are the basic parameters of experimentally identified heat generation processes in the reciprocating internal combustion engine (conventional engine) under the shaft rotation frequency $n_{\mathrm{e}}=2400 \min ^{-1}\left(p_{e}\right.$ - average effective pressure in engine's cylinder; as it has been already stated $\varphi_{\Pi}$ and $\varphi_{\mathrm{K}}$ - the angles of the crankshaft turn-over under which the perceptible process of fuel combustion starts and terminates; $\Delta \varphi$ - the angled duration of the combustion process; $\varphi_{\max }$ - angled position of the crankshaft under which the intensiveness of the combustion is the highest; $Q_{\text {тЦ }}$ - potentially possible heat generation defined by the quantity of fuel injected into the engine's working space and by its heat generating capacity; $\oint_{\max }=(d Q / d \varphi)_{\max }$ and $\mathcal{Q}_{\mathrm{sr}}=(d Q / d \varphi)_{\mathrm{sr}}-$ maximal and average value of heat generation analogue fixed by a computer).

Parameters of average heat generation processes

\begin{tabular}{|c|c|c|c|c|c|}
\hline$p_{e}, \mathrm{MPa}$ & 0 & 0.10 & 0.19 & 0.30 & 0.45 \\
\hline$\varphi_{\Pi}, \mathrm{deg}$ & -4.03 & -10.75 & -10.83 & -13.45 & -13.48 \\
\hline$\varphi_{\mathrm{K}}, \mathrm{deg}$ & 116.00 & 93.57 & 78.44 & 67.19 & 63.90 \\
\hline$\Delta \varphi, \mathrm{deg}$ & 120.03 & 104.32 & 89.27 & 80.64 & 77.38 \\
\hline$\varphi_{\max }, \operatorname{deg}$ & 59.94 & 42.61 & 33.44 & 18.16 & 16.64 \\
\hline$Q_{\mathrm{TL}}, \mathrm{J}$ & 549.54 & 609.18 & 706.31 & 865.59 & 994.28 \\
\hline$\oint_{\max }, \mathrm{J} / \mathrm{deg}$ & 7.47 & 11.38 & 15.51 & 25.55 & 34.98 \\
\hline$\oint_{\mathrm{Sr}}, \mathrm{J} / \mathrm{deg}$ & 4.23 & 5.38 & 7.69 & 10.31 & 12.26 \\
\hline$\oint_{\max } / \oint_{\mathrm{Sr}}$ & 1.77 & 2.12 & 2.02 & 2.48 & 2.85 \\
\hline$\tau^{*}$ & 0.53 & 0.51 & 0.50 & 0.39 & 0.39 \\
\hline$\xi^{*}$ & 1.63 & 1.95 & 1.96 & 2.60 & 2.72 \\
\hline$\xi^{*} \tau^{*}$ & 0.86 & 0.99 & 0.98 & 0.93 & 1.06 \\
\hline$m$ & 1.59 & 1.91 & 1.88 & 1.75 & 2.08 \\
\hline$-a$ & 3.37 & 4.66 & 4.81 & 8.48 & 12.28 \\
\hline
\end{tabular}

Taking into consideration the correlations (3)-(5), it is easy to define the parameters that appear in the table:

- conventional moment of achieving the maximum of intensiveness (maximum of capacity, speed) of heat generation

$$
\tau^{*}=\frac{\varphi_{\max }-\varphi_{\Pi}}{\varphi_{\mathrm{K}}-\varphi_{\Pi}}
$$

- relative maximal intensiveness (capacity, speed) of heat generation

$$
\&=\frac{\varphi_{\mathrm{K}}-\varphi_{\Pi}}{Q_{\mathrm{T}}} \&_{\max }
$$


- parameters $m$ and $a$, that are solutions to simultaneous equations

$$
\tau^{*}=m \exp \left(-\frac{m}{m+1}\right), a=-\frac{m}{m+1} \frac{1}{\tau^{* m+1}} .
$$

The acquired information (see the table) is succeeded by the following: there are more reasons to consider as fixed in advance the value of the parameter $m$, rather than the parameter $a$. Given, for example, $\varepsilon^{*} \approx 1$, it is possible to acknowledge that $m \approx 1,93$. And assuming that $m \approx 2$ one has to acknowledge that $\leqslant \tau^{*} \approx 1,03$. Consequently, the assumption that $a=-6,908$ (as referred to $[13,20]$ and others) considerably limits the flexibility and preciseness of the identification algorithm.

The connection between the parameters $\tau^{*}$ and ${ }^{*}$ is illustrated by the Fig. 14. It is obvious that in empirical meaning regime points $1 \ldots .5$ (see also the table) seem to belong to a certain (parabolic, presumably) curve $K r$. But theoretically it appeared that they should have belonged to a fuzzy hyperbola $G p$, limited by unambiguous hyperbolas $\leqslant \tau^{*}=1$ та $\leqslant \tau^{*}=1,03$. The fact that the point 1 does not coincide with the defined tendency is the sign of imperfection of engine's idle run rather than the denial of general theoretically substantiated regularity. Other essential irregularities can also result from either incorrect calibration of the engine regime or from the failure in experiments planning [21].

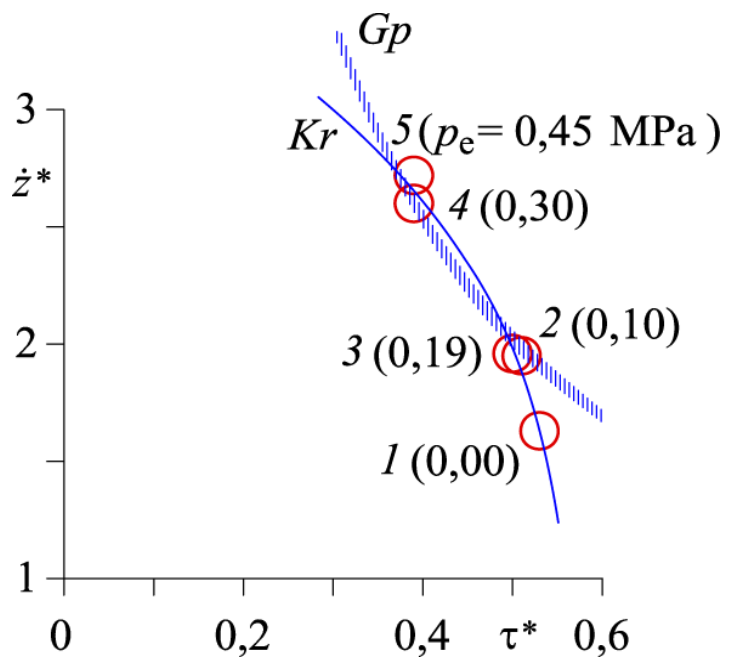

Fig. 14. Interrelation of parameters

Certainly, the results of the conducted research to the great extend embody certain concrete experimental (empirical) information. Experimenting is resorted to even in the domain of mathematics (suffice it to mention the ideas expressed in this respect in [22]). Generally speaking, many mathematicians unconditionally believed that the main methods to comprehend the truth are induction and analogy (not necessary mathematical).

\section{Conclusions}

The research of heat generation and heat consumption in a conventional or ideal engine provides useful information about the regularities, character of the process and effectiveness of fuel combustion in any real engine that cannot be subject to experiments. This information is advantageous both in case of heat transformation effectiveness analysis and the development of means to improve already employed engine.

The theoretical isochoric thermodynamic cycle serves as a sample for an otto-engine operation cycle. Thus the correlation of operations in a real process with the operations in an isochoric one could be considered as index of identity between real and seemingly ideal heat generation. Similar context allows to speak about the level of isochoric heat leakage (heat loss) into the cylinder walls within the real operating cycle. However, this comprehension of ideality is not beneficial. On the contrary, we should admit, the 
isochoric process (as well as adiabatical or isothermal) cannot serve as an ideal example of either heat generation, or heat consumption.

It has become clear (and easily explained) that under the increase of the load the maximal intensiveness (speed, capacity) of heat emission accelerates and moves towards the TDC of the piston, whereas the duration of the combustion process decreases. When the frequency of the engine shaft rotation accelerates the heat generation in the proximity of the top dead center becomes less intensive and prolonged according to the angle of the engine shaft turn-over. In general, the course of heat generation process is commonly characterized by the index $m>0$ of fuel burn-out quality and the index of capacity of combustion. This approach to the identification of processes in the internal combustion engines appeared to be rather effective.

As a rule in case of analytical identification of heat generation - heat consumption processes the index $a$ of combustion capacity is defined in advance. The acquired information, however, demonstrates that there are more reasons to consider the value of the parameter $m$ to be set in advance, rather than of the parameter $a$.

The relation between values of heat emission maximal intensiveness and the time of its achievement $\tau^{*}$ in an empirical sense is seemingly parabolic. Theoretically, as it has been found out, it can be evidently treated as "fuzzy" hyperbolic. The fact that the engine's idle run does not conform to the "hyperbolic" tendency manifests its considerable imperfection and does not contend against the theoretically substantiated regularity. Given, for example, that $\approx \tau^{*} \approx 1$, it is possible to acknowledge that $m \approx 1,93$. While given $m \approx 2$, we will have to acknowledge that $\kappa^{*} \approx 1,03$. Thus, if we assign in advance that $a=-6,908$ (as usual) we considerably limit the flexibility and preciseness of the identification algorism.

\section{References}

[1] N. Ninic, M. Grljušic, and M. Jelic, "Decomposition method as a new type of second law analysis of the combustion process of internal combustion engines", International Journal of Exergy, vol. 10, no. 1, pp. 1-20, 2012.

[2] E. Meeks, et al., "New modeling approaches using detailed kinetics for advanced engines", in Proc. 7th Int. Conf. on Modeling and Diagnostics for Advanced Engine Systems, COMODIA, 2008, pp. 469-474.

[3] C. V. Naik, et al., "Applying detailed kinetics to realistic engine simulation: The surrogate blend optimizer and mechanism reduction strategies", SAE International Journal of Engines, vol. 3, no. 1, pp. 241-259, 2010.

[4] J. M. Borg, and A. C. Alkidas, "On the application of Wiebe functions to simulate normal and knocking spark-ignition combustion”, International Journal of Vehicle Design, vol. 49, no. 1-3, pp. 52-69, 2009.

[5] J. I. Ghojel, "Review of the development and applications of the Wiebe function: A tribute to the contribution of Ivan Wiebe to engine research", International Journal of Engine Research, vol. 11, no. 4, pp. 297-312, 2010.

[6] S. Hu, H. Wang, C. Yang, and Y. Wang, "Burnt fraction sensitivity analysis and 0-D modelling of common rail diesel engine using Wiebe function", Applied Thermal Engineering, Vol. 115, pp. 170-177, 2017.

[7] "Kraftfahrzeugmotoren: Auslegung und Konstruktion / Herausgegeben von Volkmar Küntscher", Berlin, Germany: Verlag Technik, 1989. [in German].

[8] V. N. Lucanin, et al., "Dvigateli vnutrennego sgoraniya" ["Internal combustion engines"], in Theory of Workflows, vol. 1. Moscow, Russia: Vysshaya shkola Publ., 1995. [in Russian].

[9] P. Hashchuk, T. Mys'kiv, and S. Nikipchuk, Avtomobil'ni dvyhuny. Teplovyy ta dynamichnyy rozrakhunok [Automobile engines. Thermal and dynamic calculation]. Lviv, Ukraine: Ukrayins'ki tekhnolohiyi Publ., 2006. [in Ukrainian].

[10] M. Zejliger, Dvigateli Dizel' povyshennoy moshchnosti [Diesel Engines of Increased Power]. Moscow, Russia: Moskovskoye akademicheskoye izdatel'stvo Publ., 1927. [in Russian].

[11] V. I. Chastuhin, and V. V. Chastuhin, Toplivo i teoriya goreniya [Fuel and combustion theory]. Kyiv, Ukraine: Vyshcha shkola Publ., 1989. [in Russian].

[12] B. N. Semenov, E. P. Pavlov, and V. P. Koptsev, Rabochiy protsess vysokooborotnykh dizeley maloy moshchnosti [Working process of high-speed diesel engines of low power]. Leningrad, Russia: Mashinostroenie Publ., 1990. [in Russian]. 
[13] B. A. Sharoglazov, M. F. Farafontov, and V. V. Klement'ev, Dvigateli vnutrennego sgoraniya: teoriya, modelirovanie $i$ raschet protsessov [Internal combustion engines: theory, modeling and calculation of processes]. Chelyabinsk, Russia: YuUrGU Publ., 2004. [in Russian].

[14] P. Hashchuk, and Yu. Bohachyk, "Analitychni zasoby modeliuvannia protsesiv teplotvorenniateplospozhyvannia $v$ dvyhuni z yaskrovym zapaliuvanniam na yalovykh rezhymakh yoho roboty" ["Analytical means for simulation of heat production-heat consumption in an engine with ash ignition on the firing modes of its work"], Proektuvannia, vyrobnytstvo ta ekspluatatsiia avtotransportnykh zasobiv i poizdiv. Pratsi zakhidnoho naukovoho tsentru Transportnoi akademii nauk [Design, manufacture and operation of motor vehicles and trains. Proceedings of the Western Scientific Center of the Transport Academy of Sciences], vol. 1, pp. 34-51, 1995. [in Ukrainian].

[15] P. Hashchuk, and Yu. Bohachyk, "Osoblyvosti vnutrishnoho teploperenosu v dvyhuni z yaskrovym zapalenniam za riznykh navantazhen" ["Peculiarities of internal heat transfer in a motor with ascorbic inflammation at different loads"], Proektuvannia, vyrobnytstvo ta ekspluatatsiia avtotransportnykh zasobiv $i$ poizdiv. Pratsi zakhidnoho naukovoho tsentru Transportnoi akademii nauk [Design, manufacture and operation of motor vehicles and trains. Proceedings of the Western Scientific Center of the Transport Academy of Sciences], vol. 2, pp. 12-15, 1995. [in Ukrainian].

[16] V. V. Vodolazhchenko, et al. Proyektirovaniye teplovoznykh dvigateley [Designing of diesel engines]. Moscow, Russia: Transport Publ., 1972. [in Russian].

[17] T. M. Melkumov, Teoriya bystrokhodnogo dvigatelya s samovosplameneniyem [Theory of a high-speed engine with self-ignition]. Moscow, Russia: Gosudarstvennoye izdatel'stvo oboronnoy promyshlennosti Publ., 1953. [in Russian].

[18] N. Kh. Dyachenko, et al. Bystrokhodnyye porshnevyye dvigateli vnutrennego sgoraniya [High-speed reciprocating internal combustion engines]. Moscow-Leningrad, Russia: Mashgiz, 1962. [in Russian].

[19] S. V. Nikipchuk, "Vyznachennya koefitsiyenta teploperedachi v dvyhuni pryvodu pozhezhnoryatuval'noho obladnannya analitychnymy zasobamy" ["Determination of the coefficient of heat transfer in the engine of the drive of fire and rescue equipment by analytical means"], in Proc. Int. Scientific and Practical Conf. Fire and technogenic safety. Theory, practice, innovations, Lviv, Ukraine, October 20-21, 2016, pp. $433-435$. [in Ukrainian].

[20] I. I. Wiebe, Brennverlauf und Kreisprozess von Verbrennungsmotoren [Burning process and cycle of internal combustion engines]. Berlin, Germany: VEB-Verlag Technik, 1970. [in Germany].

[21] P. M. Hashchuk, and S. V. Nikipchuk, "Modelno-symuliatsiina tekhnolohiia doslidzhennia termodynamichnykh protsesiv u dvyhunakh vnutrishnoho zghoriannia" ["Model-simulation technology of the study of thermodynamic processes in internal combustion engines"], in Proc. 13th Int. Symposium of Ukrainian Mechanical Engineers, Lviv, Ukraine, May 18-19, 2017, pp. 93-95. [in Ukrainian].

[22] V. L. Rvachev, and V. O. Rvachov, Eksperymental'na matematyka: metodolohiya, problemy, praktyka [Experimental Mathematics: Methodology, Problems, Practice]. Kyiv, Ukraine: Znannya Publ., 1983. [in Russian]. 